Revista

Ibero-Americana

de Estratégıa

\title{
PROSPECÇÃO DE CENÁRIOS: UMA ABORDAGEM PLURAL PARA O FUTURO DO BRASIL EM 2020
}

PROSPECCIÓN DE ESCENARIOS: UN ABORDAJE PLURAL PARA EL FUTURO DE BRASIL EN 2020

\section{SCENARIOS PROSPECTIVE: A PLURAL APPROACH TO THE FUTURE OF BRAZIL IN 2020}

\section{James Terence Coulter Wright}

Doutor em Administração pela Universidade de São Paulo - USP

Professor da Universidade de São Paulo - USP

E-mail: jtwright@ usp.br (Brasil)

\section{Antonio Thiago Benedete Silva}

Mestre em Administração pela Faculdade de Economia, Administração e Contabilidade da Universidade de São Paulo - FEA/USP

Professor da Fundação Escola de Comércio Álvares Penteado - FECAP

E-mail: atbenedete@usp.br (Brasil)

\section{Renata Giovinazzo Spers}

Doutora em Administração pela Faculdade de Economia, Administração e Contabilidade da Universidade de São Paulo - FEA/USP

Professora da Fundação Instituto de Administração - FIA/USP

E-mail: renatag@fia.com.br (Brasil) 


\title{
PROSPECÇÃO DE CENÁRIOS: UMA ABORDAGEM PLURAL PARA O FUTURO DO
}

BRASIL EM 2020

\section{RESUMO}

Este trabalho buscou desenvolver possíveis cenários para o Brasil em 2020 e identificar o cenário mais provável com a aplicação do método Delphi, do qual participaram 169 especialistas (100 na Rodada 1 e 69 na Rodada 2). Os resultados indicam que o Brasil poderá evoluir em um cenário de Desenvolvimento Integrado, combinando integração competitiva internacional com melhoria da inclusão social. Entretanto, segundo os especialistas consultados, há um risco considerável de ocorrer um cenário alternativo de Crescimento com Baixa Competitividade. Do ponto de vista da estratégia, este trabalho contribui ao identificar o cenário mais provável e indicar outros cenários possíveis, os quais, quando analisados em conjunto, permitem melhores decisões estratégicas pela identificação e modelagem de incertezas, antes de serem feitos comprometimentos substanciais e irreversíveis, e aumentam a velocidade de resposta a eventos inesperados pela visualização antecipatória de futuros possíveis.

Palavras-chave: Estudos do Futuro; Cenários; Desenvolvimento Econômico; Brasil.

\section{PROSPECCIÓN DE ESCENARIOS: UN ABORDAJE PLURAL PARA EL FUTURO DE} BRASIL EN 2020

\begin{abstract}
This study aimed to develop possible scenarios for Brazil in 2020 and identify the most likely scenario using the Delphi method, in which participated 169 specialists (100 in Round 1 and 69 in Round 2). The results indicate that Brazil might evolve into an Integrated Development Scenario combining international competitive integration with better social inclusion. However, according to the experts consulted, Brazil runs a considerable risk of falling in an alternative scenario, the Growth with Low Competitiveness Scenario. From the strategy point of view, this work contribution is to identify the most likely scenario and indicate other possible scenarios, which, when taken together, enable better strategic decisions by discovering and modeling uncertainties before substantial and irreversible commitments are made, and increase the speed of response to unexpected events by anticipating possible futures.
\end{abstract}

Keywords: Future Studies; Scenarios; Economic Development; Brazil.

Revista Ibero-Americana de Estratégia - RIAE, São Paulo, v. 9, n. 1, p. 56-76, jan./abr. 2010. 
James Terence Coulter Wright, Antonio Thiago Benedete Silva \& Renata Giovinazzo Spers

\section{PROSPECCIÓN DE ESCENARIOS: UN ABORDAJE PLURAL PARA EL FUTURO DE}

BRASIL EN 2020

\section{RESUMEN}

Este trabajo pretendió desarrollar posibles escenarios para Brasil en el 2020 e identificar el escenario más probable con la aplicación del método Delphi, del cual participaron 169 especialistas (100 en la Rodada 1 y 69 en la Rodada 2). Los resultados indican que Brasil podrá evolucionar en un escenario de Desarrollo Integrado, combinando integración competitiva internacional con mejoría de la inclusión social. Sin embargo, según los especialistas consultados, hay un riesgo considerable de ocurrir un escenario alternativo de Crecimiento con Baja Competitividad. Desde el punto de vista de la estrategia, este trabajo tiene una contribución al identificar el escenario más probable e indicar otros escenarios posibles, los cuales, cuando son analizados en conjunto, permiten mejores decisiones estratégicas por la identificación y modelaje de las incertidumbres, antes de hacer comprometimientos substanciales e irreversibles, y aumentan la velocidad de respuesta a eventos inesperados por la visualización anticipada de posibles futuros.

Palabras-clave: Estudios de Futuro; Escenarios; Desarrollo Económico; Brasil.

Revista Ibero-Americana de Estratégia - RIAE, São Paulo, v. 9, n. 1, p. 56-76, jan./abr. 2010. 
Prospecção de Cenários: Uma Abordagem Plural para o Futuro do Brasil em 2020

\section{INTRODUÇÃO}

Elaborar cenários não é um exercício de predição, mas sim um esforço de fazer descrições plausíveis e consistentes de situações futuras possíveis, apresentando os condicionantes do caminho entre a situação atual e cada cenário futuro, destacando os fatores relevantes às decisões que precisam ser tomadas (Wright \& Spers, 2006). Aplicado ao nível de nação, descrever cenários para um país é mapear futuros possíveis, identificar tendências e incertezas, e antecipar oportunidades e ameaças.

No mundo de hoje, cada vez mais dinâmico e interligado econômica, tecnológica e politicamente, pensar o futuro das nações tornou-se um exercício complexo e desafiador. Apesar da dificuldade, planejar, considerando futuros possíveis é preciso, e, num país com recursos escassos, escolher uma boa rota, aproveitar oportunidades e precaver-se de escolhas erradas é essencial.

Este trabalho procurou desenvolver possíveis cenários para o Brasil em 2020 e identificar o cenário mais provável com a aplicação do método Delphi, do qual participaram 169 especialistas (100 na Rodada 1 e 69 na Rodada 2). Segundo Clemen e Reilly (2001), em condições de incerteza, pode-se recorrer à uma interpretação subjetiva de probabilidade, com a probabilidade representando a opinião de indivíduos de que determinado resultado ocorrerá. No contexto da Técnica Delphi, busca-se um consenso de opiniões de um grupo de especialistas a respeito de eventos futuros, baseando-se no uso estruturado do conhecimento e da experiência, no pressuposto que o julgamento coletivo, quando organizado adequadamente, é melhor do que a opinião de um só indivíduo (Wright \& Giovinazzo, 2000). A evolução em direção a um consenso obtido no processo representa uma consolidação do julgamento intuitivo de um grupo de peritos sobre eventos futuros e tendências. Tal julgamento intuitivo pode ser aplicado à indicação de probabilidades subjetivas, como no objetivo deste trabalho de identificar o cenário mais provável no julgamento de um grupo de especialistas.

Do ponto de vista da estratégia, cenários de larga escala (large-scale scenarios) podem ajudar na formulação de estratégias e investimentos ao aumentar a robustez da estratégia por identificar e desafiar premissas subjacentes sobre o futuro, permitir melhores decisões estratégicas pela identificação e modelagem de incertezas, antes de serem feitos comprometimentos substanciais e irreversíveis, aumentar o conhecimento e o entendimento sobre o ambiente externo, e aumentar a velocidade de resposta a eventos inesperados pela visualização antecipatória de futuros possíveis.

Revista Ibero-Americana de Estratégia - RIAE, São Paulo, v. 9, n. 1, p. 56-76, jan./abr. 2010. 
James Terence Coulter Wright, Antonio Thiago Benedete Silva \& Renata Giovinazzo Spers

\section{ESTUDOS DO FUTURO, PROSPECÇÃO E CENÁRIOS}

No campo dos estudos do futuro, podem ser identificadas duas áreas de pesquisas que apresentam pressupostos e técnicas distintas, sendo elas a previsão (forecasting) e a prospecção (foresight). Nesse sentido, Jouvenel (2000) afirma que o processo prospectivo apresenta traços essenciais que o distanciam da previsão em geral. Em primeiro lugar, a prospecção usa um enfoque pluridisciplinar de inspiração sistêmica baseado no princípio de que os problemas não podem ser corretamente compreendidos se reduzidos a uma dimensão, como ocorre geralmente quando são abordados a partir de disciplinas acadêmicas distintas. Em vez disso, a prospecção oferece uma abordagem que captura as realidades em suas totalidades, com todas as variáveis que agem sobre elas, baseada no estudo de todos os fatores e suas inter-relações. Para o Departamento de Prospecção e Planejamento de Portugal (1997), pode-se ir mais longe no confronto entre as abordagens da previsão e da prospecção, conforme mostra o Quadro 1.

\begin{tabular}{|c|c|}
\hline PREVISÃO & PROSPECÇÃO \\
\hline Concentra-se nas Certezas; Oculta as Incertezas & $\begin{array}{l}\text { Concentra-se nas Incertezas, legitimando o seu } \\
\text { reconhecimento }\end{array}$ \\
\hline Origina projeções sobre um único ponto e lineares & Origina imagens diversas, mas lógicas, do futuro \\
\hline Privilegia as Continuidades & Leva em consideração as Rupturas \\
\hline Afirma o primado do Quantitativo sobre o Qualitativo & Alia Qualitativo e Quantitativo \\
\hline Oculta os Riscos & Sublinha os Riscos \\
\hline Favorece a Inércia & $\begin{array}{l}\text { Favorece uma atitude de Flexibilidade e o espírito de } \\
\text { Responsabilidade }\end{array}$ \\
\hline Parte do que é Simples para o que é Complexo & Parte do que é Complexo para o que é Simples \\
\hline Adota uma abordagem normalmente setorial & Adota uma abordagem global \\
\hline
\end{tabular}

Quadro 1 - Diferenças entre Previsão e Prospecção.

Fonte: Departamento de Prospecção e Planejamento de Portugal (1997).

Revista Ibero-Americana de Estratégia - RIAE, São Paulo, v. 9, n. 1, p. 56-76, jan./abr. 2010. 
Prospecção de Cenários: Uma Abordagem Plural para o Futuro do Brasil em 2020

A previsão, conforme mostra a coluna esquerda do Quadro 1, é amplamente apoiada por métodos estatísticos e modelagem econométrica, partindo do pressuposto que o passado é um bom preditor do futuro, podendo-se, portanto, privilegiar continuidades e certezas. Por outro lado, a prospecção, coluna direita do Quadro 1, considera que o futuro pode ser marcado por incertezas e descontinuidades, devendo-se considerá-las em uma abordagem flexível e qualitativa.

Tendo em vista os aspectos específicos que caracterizam a prospecção, uma técnica adequada para a realização de estudos dessa natureza diz respeito à Técnica de Cenários. $\mathrm{Na}$ literatura, podem ser encontradas diversas definições para o termo cenário, a partir de seu uso como ferramenta de prospecção do futuro. Wright e Spers (2006) afirmam que elaborar cenários não é um exercício de predição, mas sim um esforço de fazer descrições plausíveis e consistentes de situações futuras possíveis, apresentando os condicionantes do caminho entre a situação atual e cada cenário futuro, destacando os fatores relevantes às decisões que precisam ser tomadas. Schnaars e Topol (1987) afirmam que o termo cenário é a combinação de três características básicas: narrativas fluídas, múltiplas projeções e progressão de eventos. Segundo estes autores, cenários são mais estruturados por narrativas fluídas do que por estimativas quantitativas precisas, ou seja, busca mais comunicar a direção geral da mudança do que predizer o futuro com precisão numérica. Essa característica oferece aos usuários insight sobre o progresso e o mecanismo da mudança. Fahey e Randall (1998) complementam afirmando que cenários são narrativas de projeções alternativas plausíveis de uma parte específica do futuro, oferecendo descrições contrastantes de como vários aspectos incertos do futuro podem se desenvolver.

Pontua Huss (1988) que o resultado mais importante da ferramenta não é predizer exatamente a sequência de eventos, antes disso, deve oferecer entendimento sobre a dinâmica do ambiente, as tendências-chave para monitorar e os limites dos desfechos do futuro para o qual se pretende planejar. Esses insights auxiliam os tomadores de decisão, se não a prever pontos de inflexão, pelo menos a acessá-los quando as condições são corretas para uma mudança estrutural de maior porte. Para que os cenários sejam elaborados, é necessário, portanto, que o cenarista considere um conjunto de forças que atuam sobre o sistema em estudo. Entretanto, a consideração de tais forças não deve se limitar à extrapolação de tendências passadas. É preciso ir além e adotar uma abordagem pluralista do futuro, balizada por forças restritivas e por forças propulsoras que atuam sobre as variáveis do sistema, bem como os limites naturais ou sociais dentro dos quais as variáveis podem evoluir no horizonte de tempo em análise. A Figura 1 apresenta esquematicamente esta visão, com base nas definições de Wright e Spers (2006), Schnaars e Topol (1987), Fahey e Randall (1998) e Huss (1988).

Revista Ibero-Americana de Estratégia - RIAE, São Paulo, v. 9, n. 1, p. 56-76, jan./abr. 2010. 
James Terence Coulter Wright, Antonio Thiago Benedete Silva \& Renata Giovinazzo Spers

Figura 1 - Visão Esquemática do Conceito de Cenários.

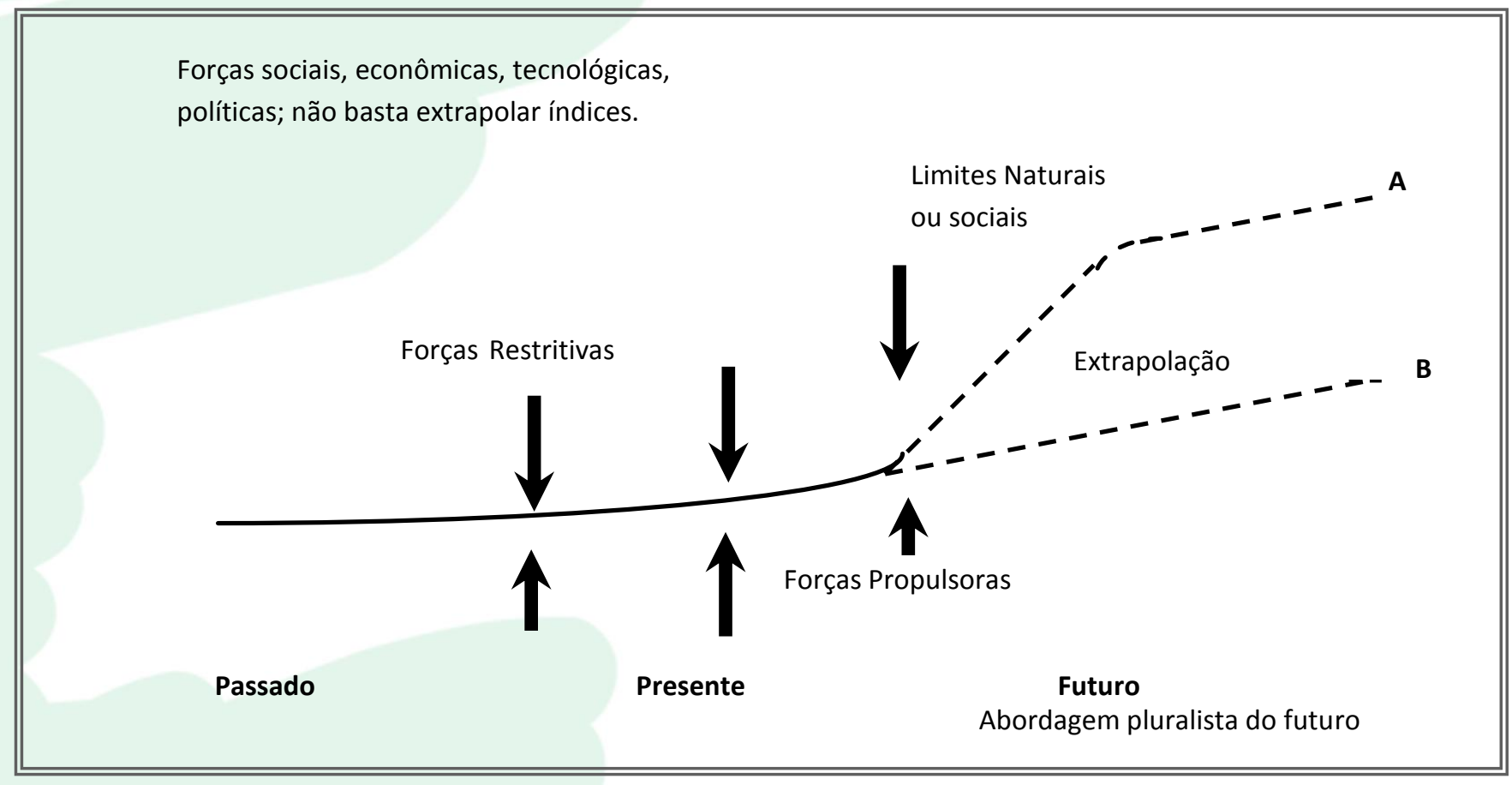

Fonte: Elaborada pelos autores.

Um fator fundamental a ser considerado na decisão de utilização da ferramenta é o elemento incerteza. Há consenso que o mundo hoje é caracterizado por um estado de constantes transformações. Nesse sentido, Huss (1988) afirma que cenários são mais adequados quando aplicados a longo prazo e à análise macro de ambientes incertos, os quais podem ser tipificados por escassez de dados e um grande número de fatores não quantificáveis. Para o autor, cenários não identificam perturbações de curto prazo no sistema; a abordagem enfatiza relações e tendências de longo prazo (10-20 anos). Assim como Huss (1988), Schoemaker (1995) afirma que organizações podem se beneficiar com o planejamento de cenários quando a incerteza é alta em relação à habilidade dos gerentes de predizer ou ajustar.

Tendo em vista que em sua essência cenários são descrições plausíveis do futuro de um determinado sistema, é fundamental identificar a natureza das descrições que podem ser feitas. Segundo Masini e Vasquez (2000), as diferentes escolas de pensamento sobre a elaboração de cenários adotam um conjunto de tipos, conforme mostra o Quadro 2, visto que, em linhas gerais, os cenários podem ser tendenciais ou extrapolativos, normativos ou desejáveis, catastróficos, utópicos e contrastantes.

Revista Ibero-Americana de Estratégia - RIAE, São Paulo, v. 9, n. 1, p. 56-76, jan./abr. 2010. 
Prospecção de Cenários: Uma Abordagem Plural para o Futuro do Brasil em 2020

\begin{tabular}{|c|c|}
\hline ESCOLAS & TIPOS E DEFINIÇÕES \\
\hline \multirow{3}{*}{$\begin{array}{l}\text { Cenários Extrapolativos e } \\
\text { Normativos: Erich Jantsch }\end{array}$} & $\begin{array}{l}\text { Cenários Extrapolativos usam dados referentes ao passado e ao presente, tendo em vista } \\
\text { o que é possível e provável. }\end{array}$ \\
\hline & $\begin{array}{l}\text { Cenários Normativos são projetados do futuro para o presente, retornando ao futuro } \\
\text { novamente. }\end{array}$ \\
\hline & $\begin{array}{l}\text { Cenários Extrapolativos podem ser também normativos quando, além de contemplar o } \\
\text { que é possível e provável, contemplam o que é desejável. }\end{array}$ \\
\hline \multirow{2}{*}{$\begin{array}{l}\text { Cenários Prováveis e } \\
\text { Desejáveis: Escola Francesa }\end{array}$} & $\begin{array}{l}\text { Cenários Prováveis correspondem ao que acontecerá no futuro, a partir do conhecimento } \\
\text { das atividades dos atores. }\end{array}$ \\
\hline & $\begin{array}{l}\text { Cenários Desejáveis indicam o horizonte para o qual se deve direcionar os esforços } \\
\text { quando se quer que as coisas se modifiquem significativamente e quando pretende-se ir } \\
\text { além dos prognósticos do cenário provável, provendo uma solução para os problemas } \\
\text { que emergem do sistema. }\end{array}$ \\
\hline \multirow{2}{*}{$\begin{array}{l}\text { Cenários de Primeira e } \\
\text { Segunda Geração: Escola } \\
\text { Shell-SRI }\end{array}$} & $\begin{array}{l}\text { Cenários de Primeira Geração são usualmente exploratórios e possuem as seguintes } \\
\text { características: ajudam a obter um melhor entendimento da realidade e são capazes de } \\
\text { levantar de forma melhor as questões; não oferecem auxílio maior para a tomada de } \\
\text { decisão; são orientados para o entendimento e não para a ação. }\end{array}$ \\
\hline & $\begin{array}{l}\text { Cenários de Segunda Geração são baseados em uma análise sólida da realidade; eles } \\
\text { modificam as premissas e suposições de decisores sobre como o mundo funciona e os } \\
\text { obriga a reorganizar seus modelos mentais de realidade; são também ferramentas } \\
\text { educacionais, pois trabalham nos mecanismos ou no mundo interno dos tomadores de } \\
\text { decisões. }\end{array}$ \\
\hline \multirow{4}{*}{$\begin{array}{l}\text { Cenários Tendenciais, } \\
\text { Otimistas, Pessimistas e } \\
\text { Contrastantes: H. Kahn e } \\
\text { Estudos dos Futuros } \\
\text { Humano e Social }\end{array}$} & $\begin{array}{l}\text { Cenários Tendenciais-Inerciais ou Cenários de Tendência: descrevem o prolongamento } \\
\text { da situação presente - o que é presente agora. Não pressupõem mudanças, como se tudo } \\
\text { fosse continuar constante, exatamente igual. }\end{array}$ \\
\hline & $\begin{array}{l}\text { Cenários Utópicos: descrevem o melhor dos mundos possíveis, qual seria a situação } \\
\text { ideal. Apesar de usualmente inatingível, o cenário utópico é o mais desejável, e tem uma } \\
\text { proposta altamente didática quando mostra o que não é atingível. }\end{array}$ \\
\hline & $\begin{array}{l}\text { Cenários Catastróficos: descrevem o pior dos mundos possíveis, piorando o que foi } \\
\text { identificado como cenário tendencial. }\end{array}$ \\
\hline & $\begin{array}{l}\text { Cenários Normativos: descrevem uma situação desejável e atingível que melhora o } \\
\text { cenário tendencial, estruturando os objetivos para o futuro. São úteis para definir um } \\
\text { certo número de metas atingíveis e razoáveis, e para definir os estágios necessários para } \\
\text { atingir as metas. }\end{array}$ \\
\hline
\end{tabular}

Revista Ibero-Americana de Estratégia - RIAE, São Paulo, v. 9, n. 1, p. 56-76, jan./abr. 2010. 


\section{Cenários Contrastantes: descrevem diferentes situações a partir de variações em determinadas variáveis-chave. Geralmente são o oposto do cenário tendencial, e apresentam situações extremas. São aqueles construídos se todas as surpresas, presumidas como improváveis no momento de sua enunciação, acontecessem. Entretanto, eles não são totalmente arbitrários e focam na descoberta por meio da análise racional de relações entre fatos que podem não estar suficientemente visíveis.}

Quadro 2 - Tipos de Cenários.

Fonte: Masini e Vasquez (2000).

No que se refere ao método de elaboração, Godet (2000) afirma que, na prática, não há um único método para o desenvolvimento de cenários, mas uma variedade de métodos para a construção, sendo alguns simplistas e outros sofisticados. Entretanto, pontua o autor que há um consenso que o termo Método de Cenários somente se aplica para uma abordagem que inclua um número de etapas específicas inter-relacionadas - análise de sistemas, retrospectiva, estratégia dos atores e elaboração de cenários. Coates (2000) sugere que cenários devem ser elaborados a partir da identificação e definição do universo de preocupação, definição das variáveis que serão importantes para moldar o futuro, identificação dos temas para os cenários e, finalmente, a criação dos cenários. Em linha semelhante, Jouvenel (2000) propõe que, basicamente, há cinco estágios para o procedimento prospectivo: definição do problema e escolha do horizonte de tempo, identificação das variáveis e construção do sistema, coleta de dados e elaboração de hipóteses, exploração de futuros possíveis e de escolhas estratégicas.

\section{TÉCNICA DELPHI}

A Técnica Delphi passou a ser disseminada no começo dos anos 60, com base em trabalhos desenvolvidos por Olaf Helmer e Norman Dalker, pesquisadores da Rand Corporation (Estes \& Kuespert, 1976). O objetivo original era desenvolver uma técnica para aprimorar o uso da opinião de especialistas na previsão tecnológica. Na metodologia desenvolvida, isto era feito estabelecendose três condições básicas: o anonimato dos respondentes, a representação estatística dos resultados e o feedback de respostas do grupo para reavaliação nas rodadas subsequentes (Martino, 1993). Ao longo do tempo, o método passou a ser utilizado para previsão de tendências e identificação de políticas e estratégias sobre os mais diversos assuntos.

Para Wright e Giovinazzo (2000), na sua formulação original, o Delphi é uma técnica para a busca de um consenso de opiniões de um grupo de especialistas a respeito de eventos futuros, 
baseando-se no uso estruturado do conhecimento e da experiência de um painel de especialistas, no pressuposto de que o julgamento coletivo, quando organizado adequadamente, é melhor do que a opinião de um só indivíduo. A evolução em direção a um consenso obtido no processo representa uma consolidação do julgamento intuitivo de um grupo de peritos sobre eventos futuros e tendências.

O Delphi realizado pela internet, segundo Giovinazzo e Fischmann (2001), conserva as mesmas premissas características de uma pesquisa Delphi tradicional, ou seja, é mantido o anonimato dos respondentes, a representação estatística da distribuição dos resultados e o feedback das respostas do grupo para reavaliação nas rodadas subsequentes, e os resultados da primeira rodada são divulgados na internet para que possam ser considerados pelo grupo no preenchimento da segunda rodada. A sequência básica de atividades envolvidas na execução de um Delphi Eletrônico é descrita abaixo e ilustrada na Figura 2.

i) Objetivos da pesquisa: $O$ objetivo da pesquisa deve ser claramente definido, especificando o horizonte de tempo e o tipo de resultado desejado. A equipe coordenadora do Delphi deve procurar informações sobre o tema, recorrendo à literatura especializada e a entrevistas com técnicos do setor. Segundo Aaker, Kumar e Day (2001), é importante que os objetivos de pesquisa sejam traduzidos em necessidades específicas de informação. Como as hipóteses sugerem respostas possíveis para as questões expostas pelos objetivos da pesquisa, é preciso existir itens no questionário que possam levar a essas respostas.

ii) Elaboração do questionário da primeira rodada da pesquisa Delphi: Deve-se estruturar um primeiro modelo do questionário. As questões, como em outros tipos de questionários de pesquisa, devem ser cuidadosamente elaboradas. Em função das necessidades específicas do estudo, diferentes tipos de questões podem ser utilizadas. Nesta fase, é importante a interação entre os coordenadores do estudo e especialistas do setor para assegurar a correção técnica das questões formuladas. Usualmente o questionário é bastante elaborado, apresentando para cada questão uma síntese das principais informações conhecidas sobre o assunto, e eventualmente, extrapolações para o futuro.

iii) Seleção dos painelistas: Enquanto o questionário da primeira rodada é desenvolvido e testado via internet, a equipe coordenadora faz a seleção dos painelistas. Em geral, deve-se buscar uma distribuição equilibrada entre elementos de dentro e de fora da entidade interessada, 
James Terence Coulter Wright, Antonio Thiago Benedete Silva \& Renata Giovinazzo Spers

recorrendo-se a universidades, institutos de pesquisa, indústrias e outros setores da sociedade. A qualidade do resultado depende essencialmente dos participantes do estudo. Um número entre 15 e 30 painelistas é considerado um bom número, o suficiente para gerar informações relevantes, embora grupos maiores venham sendo utilizados com sucesso.

iv) Preenchimento do questionário pela internet: $O$ questionário é disponibilizado no site, utilizando um formulário cujos dados das respostas são encaminhados para uma planilha eletrônica, como o Excel, ou outra planilha adequada para a tabulação das informações. Os respondentes são comunicados por e-mail e preenchem o questionário diretamente pela internet.

v) Aplicação de estatísticas e análise dos resultados: Após um prazo determinado pela coordenação, a equipe procede à tabulação e análise, calculando a mediana e os quartis e procurando associar os principais argumentos às diferentes tendências das respostas. Após a análise da primeira rodada, a coordenação deve decidir sobre a necessidade de incorporação de novas questões na segunda rodada, o que é bastante comum. Conforme já indicado no passo anterior, as respostas ao questionário são automaticamente disponibilizadas em uma planilha para a realização da tabulação.

vi) Elaboração do questionário da segunda rodada e feedback dos resultados da rodada 1 e análise dos resultados da rodada 2: A segunda rodada do questionário Delphi apresenta obrigatoriamente os resultados do primeiro questionário, possibilitando que cada respondente reveja sua posição em face da previsão e argumentação do grupo, em cada pergunta. Por incluir os resultados da rodada anterior e, ocasionalmente, novas questões, o segundo questionário geralmente é mais extenso que o primeiro. As questões em geral objetivam a convergências de resultados da primeira rodada, e são rediscutidas à luz da argumentação dos painelistas. Novos temas são explorados ou sugeridos e discutem-se possíveis incompatibilidades entre as tendências previstas. A segunda rodada é, da mesma forma que a primeira, disponibilizada na internet. As rodadas sucedem-se até que seja atingido um grau satisfatório de convergência. No mínimo, duas rodadas são necessárias para caracterizar o processo Delphi, sendo raros os exemplos de estudos com mais de três rodadas de questionários.

vii) Conclusões gerais e relatório final disponível na Internet: Os resultados finais são processados a partir do consenso gerado pelo grupo. Estes resultados, sintéticos ou completos, a

Revista Ibero-Americana de Estratégia - RIAE, São Paulo, v. 9, n. 1, p. 56-76, jan./abr. 2010. 
Prospecção de Cenários: Uma Abordagem Plural para o Futuro do Brasil em 2020

interpretação dos dados e as considerações levantadas no processo podem ser divulgados na internet para acesso público ou restrito aos participantes, mediante utilização de uma senha, conforme os objetivos da pesquisa.

Figura 2 - Sequência de Execução de uma Pesquisa Delphi Eletrônica.

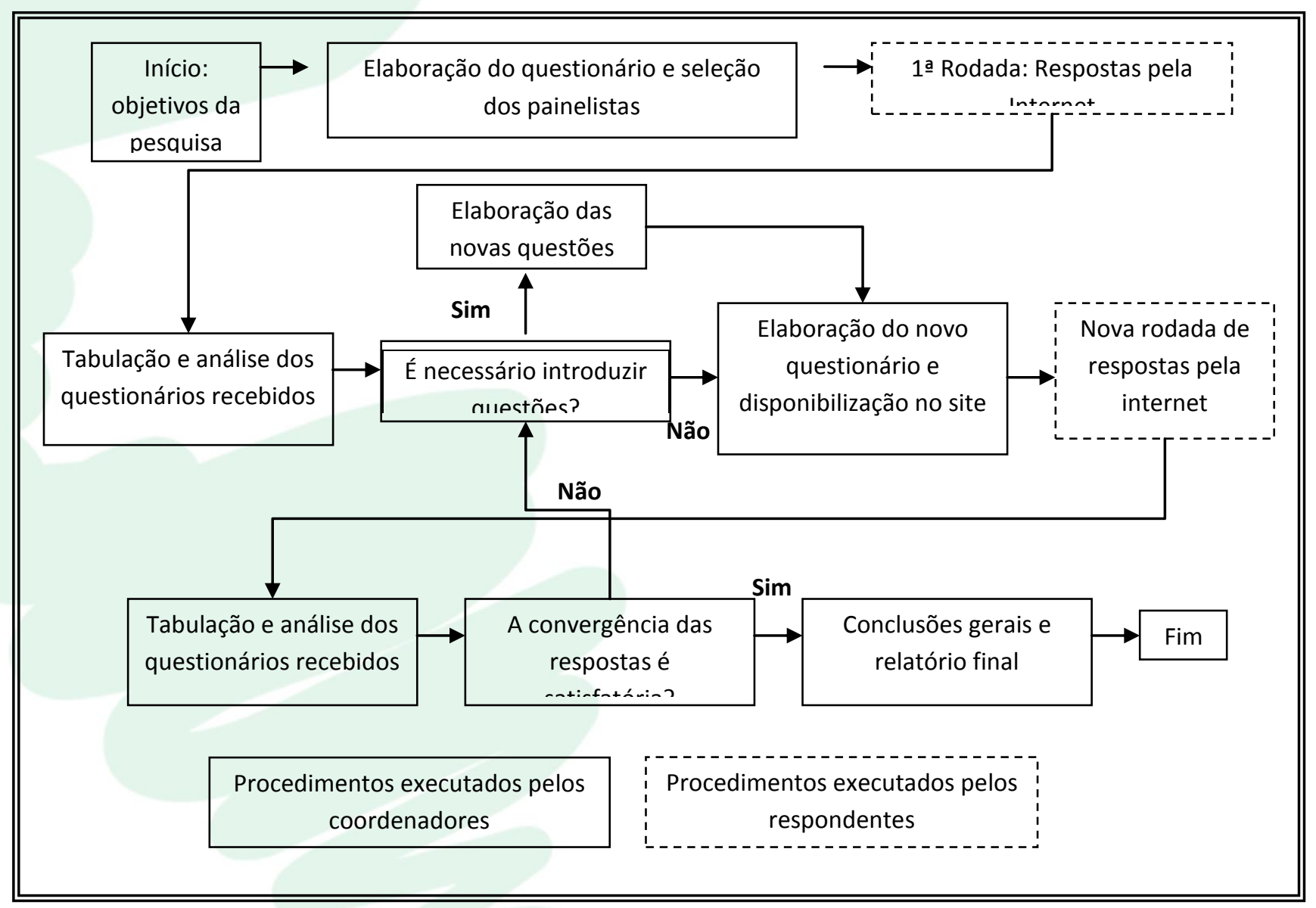

Fonte: Giovinazzo e Fischmann (2001).

É relevante ressaltar que o anonimato das respostas e o fato de não haver uma reunião física reduzem a influência de fatores psicológicos como, por exemplo, os efeitos da capacidade de persuasão, da relutância em abandonar posições assumidas e da dominância de grupos majoritários em relação a opiniões minoritárias.

Revista Ibero-Americana de Estratégia - RIAE, São Paulo, v. 9, n. 1, p. 56-76, jan./abr. 2010. 
James Terence Coulter Wright, Antonio Thiago Benedete Silva \& Renata Giovinazzo Spers

\section{BRASIL 2020: ABORDAGEM METODOLÓGICA APLICADA À PESQUISA}

A prospecção de cenários para o Brasil em 2020 foi realizada em duas etapas. A primeira consistiu na elaboração, pelos autores, dos cenários base a serem prospectados para o País. A segunda etapa consistiu em uma pesquisa em duas rodadas com a utilização da Técnica Delphi, especificamente um Delphi Eletrônico, conforme a metodologia exposta por Giovinazzo e Fischmann (2001), com a qual foi possível enriquecer os cenários base com projeções para o Produto Interno Bruto e distribuição de renda entre as famílias brasileiras. A seguir são descritos os dois processos e os resultados obtidos.

\subsection{CENÁRIOS BASE}

A construção dos cenários apoiou-se no método sugerido por Jouvenel (2000), que consiste nas seguintes etapas: definição do problema e escolha do horizonte de tempo, identificação das variáveis e construção do sistema, coleta de dados e elaboração de hipóteses, exploração de futuros possíveis e de escolhas estratégicas.

Para Jouvenel (2000), é crucial definir o problema de maneira apropriada para que a questão investigada seja clara e o terreno bem mapeado. Além disso, é importante a definição adequada do horizonte de tempo. Assim, nesta pesquisa o problema refere-se à integração do País no contexto internacional e a evolução da inclusão social, tendo em vista a construção de cenários para 2020. O passo seguinte foi a identificação das variáveis que podem influenciar esta questão, seguida pela análise das relações entre as variáveis. As variáveis identificadas foram o projeto político, o projeto econômico e o projeto social para o País. Segundo Jouvenel (2000), em seguida deve-se coletar dados e elaborar hipóteses, levando em conta três perguntas direcionadas para cada variável: Qual é o desenvolvimento passado desta variável? Qual é o desenvolvimento tendencial (extrapolação lógica)? Quais são as curvas e potenciais quebras que poderiam modificar o desenvolvimento tendencial? Orientados por essas questões foram coletados dados secundários, a partir dos quais foram explorados os cenários possíveis, conforme mostra o Quadro 3.

Revista Ibero-Americana de Estratégia - RIAE, São Paulo, v. 9, n. 1, p. 56-76, jan./abr. 2010. 


\section{Cenário 1: Desenvolvimento Integrado}

O Brasil empreenderá um projeto político social democrata, com forte melhoria do Índice de Desenvolvimento Humano e desenvolvimento econômico, integração internacional produtiva e crescimento de renda e do mercado interno. A melhoria da educação, estabilidade jurídico-institucional, eficiência do Estado e ganhos de produtividade viabilizam este cenário.

\section{Cenário 3: Modernização com Exclusão}

O Brasil desenvolverá um projeto político liberal e de Estado mínimo, dando ênfase ao processo de modernização, baseado no desenvolvimento econômico com forte integração internacional, alcançando avanços moderados no combate à pobreza.

\section{Cenário 2: Crescimento com Baixa Competitividade}

Faltará no Brasil um projeto político dominante, com integração externa parcial e isolada e fortalecimento de um Estado assistencialista e clientelista, caracterizando um quadro de pouco crescimento da economia e desempenho inferior ao dos demais países emergentes.

\section{Cenário 4: Crescimento Endógeno}

O Brasil empreenderá um projeto político reformista que promove a inclusão social e forte distribuição de renda. A economia voltar-se-á para o mercado interno, exportando apenas os excedentes. Haverá autonomia política e tecnológica e economia valorizada, evitando os eventuais custos sociais da globalização.

Quadro 3 - Cenários para o Brasil em 2020.

Fonte: Elaborado pelos autores.

Para identificar dentre esses cenários qual deles é o mais provável na visão de especialistas, procedeu-se a uma pesquisa Delphi, descrita nas seções a seguir.

\subsection{PROSPECÇÃO COM O DELPHI ELETRÔNICO}

Na segunda etapa do trabalho foi conduzida uma pesquisa Delphi, da qual participaram 169 especialistas, sendo 100 na Rodada 1 e 69 na Rodada 2. O Quadro 4 mostra o perfil dos participantes.

Tabela 1 - Perfil dos Especialistas da Pesquisa Delphi.

\begin{tabular}{|c|c|c|c|c|c|c|c|}
\hline \multicolumn{2}{|c|}{ RODADA 1 } & \multicolumn{3}{c|}{ RODADA 2 } \\
\hline Formação acadêmica & $(\%)$ & Cargo & $(\%)$ & Formação acadêmica & $(\%)$ & Cargo & $(\%)$ \\
\hline Graduação & 3 & Analista & 4 & Graduação & 12 & Analista & 9 \\
\hline Mestrado & 4 & Gerente & 43 & Mestrado & 10 & Gerente & 38 \\
\hline
\end{tabular}

Revista Ibero-Americana de Estratégia - RIAE, São Paulo, v. 9, n. 1, p. 56-76, jan./abr. 2010. 
James Terence Coulter Wright, Antonio Thiago Benedete Silva \& Renata Giovinazzo Spers

\begin{tabular}{|c|c|c|c|c|c|c|c|}
\hline Doutorado & 1 & Diretor & 43 & Doutorado & 3 & Diretor & 42 \\
\hline Pós-Doutorado & 1 & Professor & 2 & Pós-Doutorado & 1 & Professor & 3 \\
\hline MBA/especialização & 91 & Sócio & 5 & MBA/especialização & 74 & Sócio & 4 \\
\hline- & - & Consultor & 3 & - & - & Consultor & 4 \\
\hline Total & 100 & & 100 & & 100 & & \\
\hline
\end{tabular}

Fonte: Elaborado pelos autores.

O processo que estrutura a pesquisa Delphi permite o intercâmbio de ideias de forma anônima e estruturada, evitando pressões de grupo e o efeito da capacidade de argumentação de um debatedor. Geralmente, após duas ou três rodadas, é formado um consenso em torno da maioria das questões; o Delphi estabelece a troca de opiniões e, em geral, leva a uma melhor compreensão e convergência das opiniões. A evolução em direção a um consenso representa uma consolidação do julgamento intuitivo de um grupo de peritos sobre eventos futuros e tendências. A técnica baseia-se no uso estruturado do conhecimento, da experiência, e da criatividade de um painel de especialistas, no pressuposto que o julgamento coletivo, quando organizado adequadamente, é melhor do que a opinião de um só indivíduo.

O método Delphi é especialmente recomendável para horizontes de tempo muito longos, para quando não se dispõe de dados quantitativos, ou ainda quando estes não podem ser projetados para o futuro, em face de expectativa de mudanças estruturais nos fatores determinantes das tendências futuras.

\section{RESULTADOS DA PESQUISA}

Em relação aos cenários base para o País, 64\% dos especialistas apontaram o cenário Desenvolvimento Integrado como o mais provável, indicando que há uma expectativa otimista em relação à evolução do quadro político, econômico e social do Brasil. A redução do populismo e da oposição destrutiva, a inclusão das camadas mais pobres, o aumento do grau de escolaridade, o crescimento econômico sustentado pelo mercado interno e a maior inserção no comércio

Revista Ibero-Americana de Estratégia - RIAE, São Paulo, v. 9, n. 1, p. 56-76, jan./abr. 2010. 
Prospecção de Cenários: Uma Abordagem Plural para o Futuro do Brasil em 2020

internacional foram os fatores apontados pelos especialistas para fundamentar a indicação deste cenário. Além disso, o acesso à informação será ainda mais democratizado, permitindo que a população de classes econômicas inferiores encontrem um caminho para sair da pobreza absoluta. A busca dos políticos por apoio dessa nova massa de consumo forçará a implementação de novas ações para gerar emprego. Estas ações vão desencadear uma arrancada na melhoria da infraestrutura, que contará com o capital estrangeiro que vai aportar no Brasil em busca de melhores rendimentos e/ou oportunidades de longo prazo, tais como empresas para gerar energia e empresas responsáveis pela logística (estradas, ferrovias e portos).

Já para 29\% dos especialistas a expectativa é mais pessimista. O Brasil poderá evoluir em um cenário de Crescimento com Baixa Competitividade, considerando que a atual carga tributária alta comparativamente aos serviços oferecidos pelo governo, uma possível crise de crédito, a corrupção e a educação deficiente podem viabilizar este cenário para o País.

Os outros dois cenários apresentados foram percebidos como pouco prováveis, sendo o cenário Modernização com Exclusão apontado por 6\% dos especialistas e o cenário Crescimento Endógeno apontado por $2 \%$. O cenário Modernização com Exclusão é argumentado pela falta de um planejamento de longo prazo para educação e infraestrutura no Brasil. A insegurança jurídica, os problemas na previdência, o peso excessivo e ineficiência do setor público, a falta de vontade política e o personalismo foram apontados como fatores que embasam a indicação deste cenário. Enquanto o cenário de Crescimento Endógeno é acompanhado pela visão do Brasil como um País clientelista e com dificuldades de se modernizar por causa de interesses políticos mínimos.

No que diz respeito à expectativa de crescimento do Produto Interno Bruto do Brasil no período até 2020, os especialistas fizeram duas estimativas principais. Em um cenário de Desenvolvimento Integrado, o crescimento médio do PIB poderá ficar entre 4,3 e 4,5\% ao ano. $\mathrm{Na}$ visão dos especialistas, o crescimento ainda será sustentado pela estabilidade conseguida com o Plano Real, pelo crescimento do mercado interno, pela alta do preço das commodities (principalmente alimentos) e pela posição do País como grau de investimento, atraindo mais capital externo. Um crescimento maior que este pode ser limitado pela baixa qualidade da educação, melhorias tímidas na área de infraestrutura e problemas relacionados ao clientelismo, assistencialismo e populismo do governo. Outro elemento apontado pelos especialistas foi a possibilidade de haver ciclos de crescimento, com crescimento maior nos primeiros anos e restringido nos anos subsequentes em razão de um possível desaquecimento da economia mundial e de falta de reformas estruturais no País. Foi apontado, ainda, um crescimento médio do PIB de mais de 5,0\% ao ano até 2020 no cenário de Desenvolvimento Integrado. Para esses especialistas, o

Revista Ibero-Americana de Estratégia - RIAE, São Paulo, v. 9, n. 1, p. 56-76, jan./abr. 2010. 
James Terence Coulter Wright, Antonio Thiago Benedete Silva \& Renata Giovinazzo Spers

crescimento e fortalecimento do mercado interno e as vantagens do País na área de minérios, commodities agrícolas e energia viabilizariam essa projeção. A melhoria da produtividade da indústria e do setor de serviços, a modernização do parque industrial brasileiro, a facilidade de crédito, a queda gradativa dos juros e a abertura de novos mercados - como na África - são fatores que podem sustentar um crescimento médio do PIB maior que 5,0\% ao ano no período considerado.

Já em um cenário de Crescimento com Baixa Competitividade, o crescimento médio do PIB será de até 4,0\% ao ano. Para este grupo, o Brasil poderá não lograr um crescimento maior que uma taxa média de $4,0 \%$ ao ano, pois falta a solução de problemas estruturais - como na área de infraestrutura - e não há um projeto sistêmico de revisão dos gastos governamentais. As incertezas no mercado externo relativas ao crescimento da economia mundial também são fatores limitantes do crescimento. Outro fator é uma possível crise de crédito nos próximos anos.

Diante dos possíveis cenários apresentados acima, os especialistas fizeram projeções da distribuição das famílias brasileiras em classes de rendimento.

Para o cenário de Desenvolvimento Integrado, as projeções apontaram que haverá um pequena melhoria na distribuição de renda das famílias brasileiras, representada por um aumento das classes de rendimento que auferem mais de 1 até 3 salários mínimos, conforme mostra o Gráfico 1.

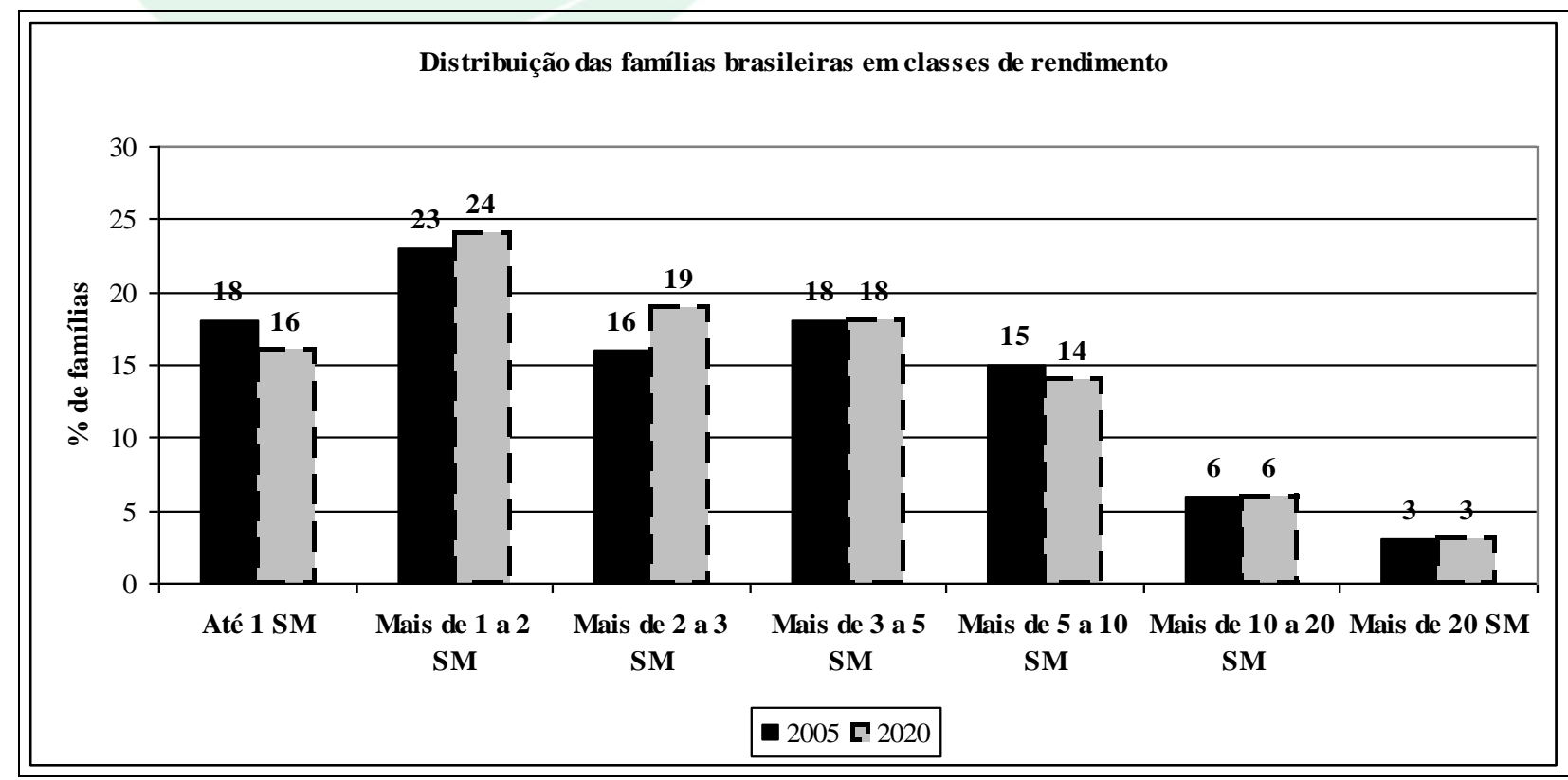

Gráfico 1 - Distribuição das Famílias Brasileiras em Classes de Rendimento no Cenário de Desenvolvimento Integrado.

Fonte: Elaborado pelos autores.

Revista Ibero-Americana de Estratégia - RIAE, São Paulo, v. 9, n. 1, p. 56-76, jan./abr. 2010. 
Isto significa que as classes de menor renda continuarão a ser parcela significativa da população do País. As últimas estimativas do Índice de Gini familiar do Brasil indicam um valor de 0,566, com tendência de queda de 1,2\% ao ano. Considerando essas estimativas, em 2020 o Índice de Gini do País estará em torno de 0,484, valor coerente com as estimativas realizadas.

Para o cenário Crescimento com Baixa Competitividade, as projeções da distribuição de famílias em classes de rendimento, conforme Gráfico 2, indicam um aumento maior nas classes populares. Estas projeções podem ser explicadas por uma possível continuidade da atual política de salário mínimo e benefícios sociais do governo federal.

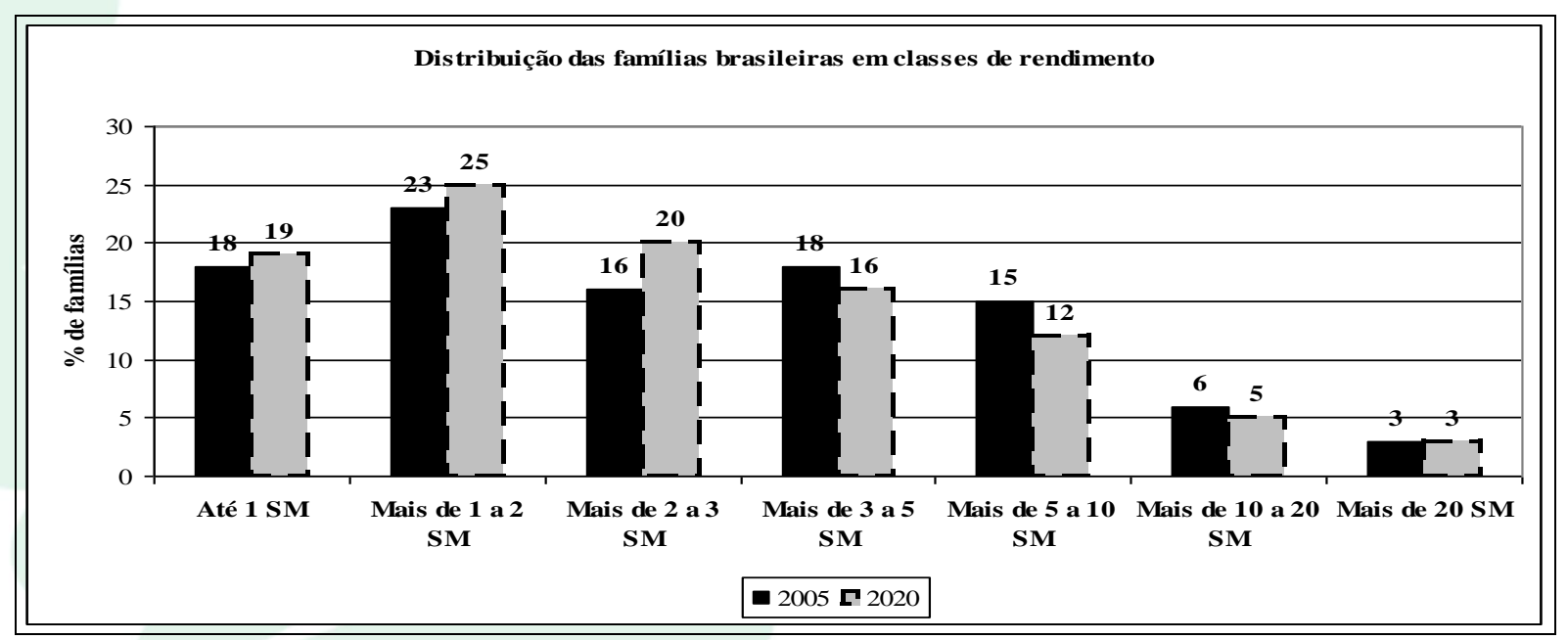

Gráfico 2 - Distribuição das Famílias Brasileiras em Classes de Rendimento no Cenário de Crescimento com Baixa Competitividade.

Fonte: Elaborado pelos autores.

\section{CONCLUSÕES}

Este trabalho buscou desenvolver possíveis cenários para o Brasil em 2020 e identificar o cenário mais provável com a aplicação do método Delphi, recorrendo-se à atribuição de probabilidades subjetivas (baseadas no julgamento de um grupo de especialistas) para identificar o cenário mais provável. Neste contexto, a probabilidade representou a opinião de indivíduos de que determinado resultado poderá ocorrer.

Os resultados indicam que a longo prazo, o Brasil poderá evoluir em um cenário de Desenvolvimento Integrado, combinando integração competitiva internacional com melhoria da inclusão social. Tal cenário será acompanhado de um crescimento médio do PIB de 4,5\% ao ano e da continuação da tendência de melhoria de distribuição de renda. Na visão dos especialistas, o

Revista Ibero-Americana de Estratégia - RIAE, São Paulo, v. 9, n. 1, p. 56-76, jan./abr. 2010. 
James Terence Coulter Wright, Antonio Thiago Benedete Silva \& Renata Giovinazzo Spers

crescimento ainda será sustentado pela estabilidade conseguida com o Plano Real, pelo crescimento do mercado interno, pela alta do preço das commodities (principalmente alimentos) e pela posição do País como grau de investimento, atraindo mais capital externo.

Entretanto, corre-se um risco considerável de o País cair em um cenário alternativo, de Crescimento com Baixa Competitividade, acompanhado por um crescimento médio do PIB de no máximo $4 \%$ ao ano. Para esse grupo de especialistas, o Brasil poderá não lograr um crescimento maior, pois falta a solução de problemas estruturais - como na área de infraestrutura - e não há um projeto sistêmico de revisão dos gastos governamentais. As incertezas no mercado externo relativos ao crescimento da economia mundial também são fatores limitantes do crescimento.

A análise conjunta dos cenários globais para o País, das projeções de distribuição de renda das famílias brasileiras e das expectativas em relação ao crescimento do PIB revela que há expectativas que o Brasil continuará o processo de alinhamento com a economia globalizada e, a despeito das recentes melhorias da distribuição, a desigualdade de renda continuará a ser característica marcante da sociedade brasileira. Entretanto, as melhorias de distribuição atingidas gerarão oportunidades a serem exploradas no mercado interno, principalmente nas classes de renda mais baixa.

A inserção no mercado externo, com reflexos diretos no crescimento do PIB, será impulsionada pela exploração de competências relativamente bem desenvolvidas no País, principalmente na área energética e agrícola. $\mathrm{O}$ crescimento de renda nos países emergentes e a produção de combustíveis a partir de cana-de-açúcar representam uma janela de oportunidades para o País, haja vista o potencial do Brasil de atender a demanda crescente por alimentos e por fontes renováveis de energia.

Os desafios a serem superados estão principalmente relacionados à melhoria qualitativa da educação, à disponibilidade de infraestrutura para viabilizar o crescimento e à superação de ineficiências na esfera político-institucional.

Os cenários de longo prazo fornecem informações de grande valia que antecipam futuras oportunidades a tempo de serem tratadas favoravelmente, assim como identifica ameaças que poderão prejudicar o dinamismo do País. Com estas informações também são criadas as condições para que as forças e fraquezas do País sejam dimensionadas em cada um dos cenários, e que estratégias favoráveis sejam desenvolvidas. O objetivo da formulação dos cenários não é o de adivinhar o futuro, mas sim o de habilitar os decisores de esferas públicas a criarem políticas resilientes às incertezas e contratempos que o futuro certamente reserva.

Revista Ibero-Americana de Estratégia - RIAE, São Paulo, v. 9, n. 1, p. 56-76, jan./abr. 2010. 
Prospecção de Cenários: Uma Abordagem Plural para o Futuro do Brasil em 2020

\section{REFERÊNCIAS}

Aaker, D. A., Kumar, V. \& Day, G. S. (2001). Pesquisa de marketing (p. 752). São Paulo: Atlas.

Clemen, R. \& Reilly, T. (2001). Making hard decisions with decision tools (p. 733). Belmont: Duxbury.

Coates, J. F. (2000, setembro). Scenario planning. Technological Forecasting and Social Change, 65(1), 115-123. http://dx.doi.org/10.1016/S0040-1625(99)00084-0

Departamento de prospecção e planejamento de Portugal. (1997). Prospecção e cenários: uma breve introdução metodológica. Lisboa, Portugal: Departamento de prospecção e Planejamento.

Estes, G. M. \& Kuespert, D. (1976). Delphi in industrial forecasting. Chemical and Engineering News (pp. 40-47). http://dx.doi.org/10.1021/cen-v054n035.p040

Fahey, L. \& Randall, R. M. (1998). Learning from the future: competitive foresight scenarios (p. 464). New York: Wiley.

Giovinazzo, R. \& Fischmann, A. A. (2001). Delphi eletrônico: uma experiência de utilização da metodologia de pesquisa e seu potencial de abrangência regional. In: XIV Congreso Latinoamericano de Estratégia. Buenos Aires, Argentina.

Godet, M. (2000, setembro). The art of scenarios and strategic planning: tools and pitfalls. Technological Forecasting and Social Change, 65(1), 3-22.

http://dx.doi.org/10.1016/S0040-1625(99)00120-1

Huss, W. R. (1988). A move toward scenario analysis. International Journal of Forecasting, 4(3), 377-388.

http://dx.doi.org/10.1016/0169-2070(88)90105-7

Jouvenel, H. (2000, setembro). A brief methodological guide to scenario building. Technological Forecasting and Social Change, 65(1), 37-48.

http://dx.doi.org/10.1016/S0040-1625(99)00123-7

Martino, J. P. (1993). Technological forecasting for decision making (3rd ed.). New York: Mc Graw-Hill.

Masini, E. \& Vasquez, J. (2000, setembro). Scenarios as seen from a human and social perspective. Technological Forecasting \& Social Change, 65(1), 49-66.

http://dx.doi.org/10.1016/S0040-1625(99)00127-4

Revista Ibero-Americana de Estratégia - RIAE, São Paulo, v. 9, n. 1, p. 56-76, jan./abr. 2010. 
James Terence Coulter Wright, Antonio Thiago Benedete Silva \& Renata Giovinazzo Spers

Schnaars, S. P. \& Topol, M. T. (1987). The use of multiple scenarios in sales forecasting. International Journal of Forecasting, 3(3-4), 405-419.

http://dx.doi.org/10.1016/0169-2070(87)90033-1

Schoemaker, P. J. H. (1995). Scenario planning: a tool for strategic thinking. Sloan Management Review, 25-40.

Wright, J. T. C. \& Giovinazzo, R. A. (2000, $2^{\circ}$ trimestre). Delphi - Uma ferramenta de apoio ao planejamento prospectivo. Caderno de Pesquisas em Administração, 1(12), 54-65.

http://dx.doi.org/10.1590/S0103-40142006000100003

Wright, J. T. C. \& Spers, R. G. (2006, janeiro/abril). O país no futuro: aspectos metodológicos e cenários. Estudos Avançados, 20(56), 13-28.

Recebido: 15/12/2009

Aprovado: 20/02/2010

Revista Ibero-Americana de Estratégia - RIAE, São Paulo, v. 9, n. 1, p. 56-76, jan./abr. 2010. 